\title{
Kaffee hat keinen Einfluss auf die Manneskraft
}

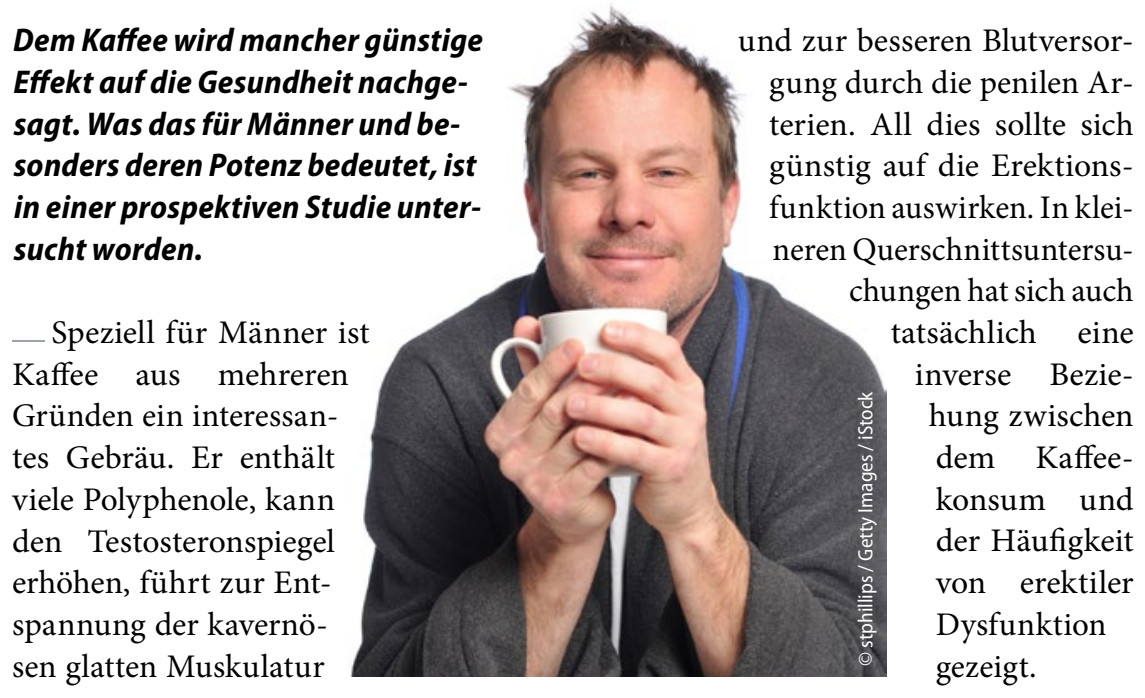

Forscher von der University of Texas in Houston haben den Zusammenhang nun in einer prospektiven Studie mit mehr als 20.000 Teilnehmern (mittleres Alter 62 Jahre) der Health Professionals Follow-Up Study überprüft.

Während der zehnjährigen Beobachtungsphase betrug die Inzidenz von erektiler Dysfunktion 34\%. Eine Assoziation mit der Menge des täglich getrunkenen Kaffees war nicht festzustellen, weder im positiven noch im negativen Sinn.

- Lopez DS et al. Coffee intake and incidence of erectile dysfunction. Am J Epidemiol 2017, online 23. August

\section{Geteiltes Leid}

\section{Diabetes beim Partner erhöht das eigene Risiko}

\section{Menschen, die mit einem Partner zu- sammenleben, bei dem kürzlich Dia- betes diagnostiziert wurde, entwickeln viel häufiger ebenfalls einen solchen als Personen mit stoffwechselgesun- den Partnern.}

_ Wenn bei einem Patienten ein Diabetes festgestellt wird, lohnt es sich, auch dessen Partner im Auge zu behalten. $\mathrm{Zu}$ dieser Überzeugung gelangten Wissenschaftler von der Emory University in Atlanta, die in einer retrospektiven Kohortenstudie Daten von etwa 3,5 Millionen Personen des Kaiser Permanente Northern California (KNPC) aus den Jahren 2007 bis 2011 analysiert hatten.

Bei den Partnern neu erkrankter Diabetiker ermittelten sie eine jährliche $\mathrm{Di}$ abetesinzidenz von 16,4/1.000/ Personen. Diese war fast elfmal so hoch wie die Er- krankungsrate von Menschen, deren Partner nicht an Diabetes litten, und nahezu doppelt so hoch wie in der Allgemeinbevölkerung (8,3/1.000). Besonders anfällig für einen solchen "partnerschaftlichen Befund" waren die Männer $(22,4 / 1.000$ vs. $12,8 / 1.000$ weibliche Partner). In der multivariaten Analyse, in die sozioökonomische Faktoren sowie Lebensstil und gesundheitliche Aspekte einflossen, war die Erkrankungshäufigkeit ein Jahr nach der Diabetesdiagnose des Partners immer noch um das 8,7-Fache erhöht.

Auch drei Jahre nach der Diagnose zeigten sich noch deutliche Unterschiede gegenüber Paaren mit stoffwechselgesunden Partnern $(45 / 1.000$ vs. $11,7 / 1.000)$ a st - Cunningham SA et al. Prev Med 2017, online 17. August

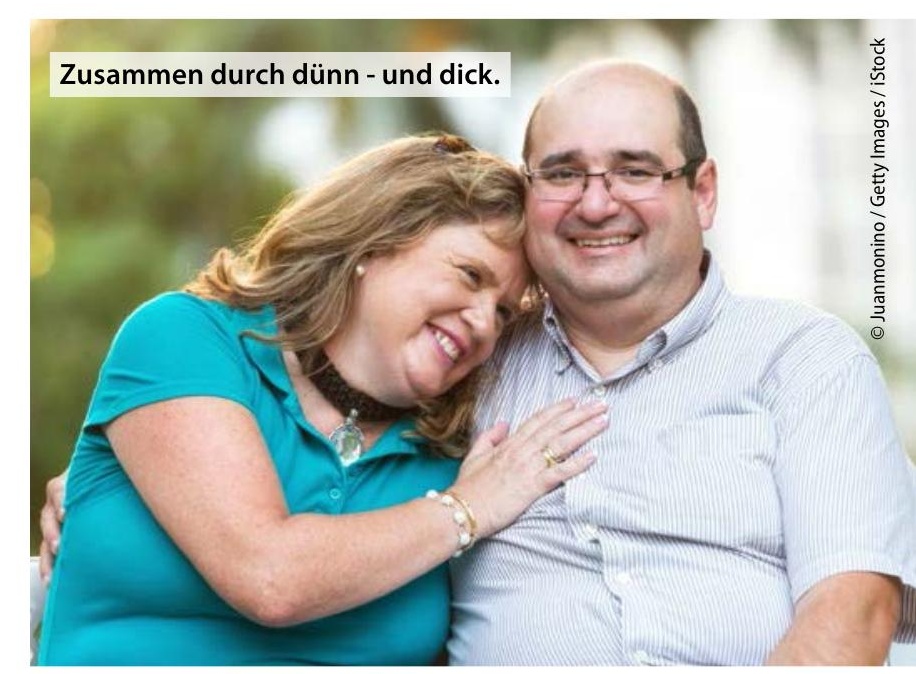

